\title{
Análise da percepção do visitante sobre a revitalização da orla marítima: o modelo do Parque Linear Calçadão, Itapema - Santa Catarina - Brasil
}

\author{
Analysis of visitor sense on the revitalization of the sea front: the model \\ of Linear Park Boardwalk, Itapema - Santa Catarina - Brazil
}

\section{Análisis de la percepción del visitante con relación a la revitalisación de la orla: el modelo del Parque Lineal de Itapema - Santa Catarina - Brasil}

\author{
Maria Emília Martins da Silva ${ }^{1}$ \\ Eduardo Juan Soriano-Sierra ${ }^{2}$
}

\begin{abstract}
Resumo: Os destinos turísticos de sol e praia preconizam pelo gerenciamento do espaço costeiro segundo os princípios da sustentabilidade, na perspectiva de desenvolver, de forma sistêmica, suas funções econômicas e ambientais. Neste contexto, o estudo analisa a percepção ambiental dos visitantes do município de Itapema (SC) sobre a revitalização da orla marítima, a partir da implantação do Parque Linear Calçadão, resultado do processo de implementação do Projeto Orla no município. Os métodos adotados para a investigação estão consubstanciados no paradigma interpretativista, que aborda uma visão subjetiva dos fenômenos sociais, embasando metodologicamente o método estudo de caso. O aporte principal da pesquisa se desenvolveu por meio da técnica de entrevista semiestruturada com nove informantes do destino e, foram posteriormente, analisadas segundo o método do Discurso do Sujeito Coletivo (DSC). Os resultados demonstraram a satisfação dos visitantes (turistas e excursionistas) com a revitalização da orla marítima e com a estrutura do Parque Linear Calçadão. Seus depoimentos evidenciaram a valorização da orla como espaço público de lazer, favorecendo atividades turístico-recreativas no espaço praial com segurança, sociabilidade e mobilidade aos frequentadores. Aspectos citados como ordenamento da orla, estrutura para fruição do lazer pelas distintas faixas etárias, contemplação da paisagem, preservação da vegetação e, a valorização da imagem do município também foram confirmadas na pesquisa como pontos positivos. Considera-se, a partir do estudo, que as cidades costeiras devem revitalizar seus espaços naturais e assegurá-los para o bem estar dos residentes e visitantes, guiando-se pelos programas de gestão existentes em nível estadual e federal, a exemplo do Projeto Orla.
\end{abstract}

Palavras-chave: Turismo de sol e praia. Zona costeira. Gestão da Sustentabilidade. Projeto Orla.

Abstract: The tourist destinations related to sun and beach need a management of coastal areas in accordance with the principles of sustainability from the perspective of developing, in a systemic way, their economic and environmental functions. In this context, the study examines the environmental perception of visitors to the city of Itapema (SC) on the revitalization of the sea front, since the implementation of the Linear Park Boardwalk, as a result of the implementation of Orla project on the city. The methods adopted for research are based on the interpretive paradigm, which addresses a subjective view of social phenomena, methodologically supporting the case study

1 Instituto Federal de Educação, Ciência e Tecnologia Catarinense. E-mail: emilia@ifc-sombrio.edu.br

2 Universidade Federal de Santa Catarina (UFSC). E-mail: sierra_ejs@yahoo.com.br 
method. The main contribution of the research was developed through semi structured interviews with nine informants, were subsequently analyzed using the method of the Collective Subject Discourse (CSD). The results demonstrated the satisfaction of visitors (tourists and excursionists) to the revitalization of the sea front and the structure of the Linear Park Boardwalk. Their evidences revealed the recovery of the sea front as a public recreational space, favoring tourist - recreational activities in beach space, safely, sociability and mobility. Local aspects cited as the sea front structure to enjoyment of leisure by different age groups, observing the landscape, preservation of vegetation and enhance the image of the municipality were also confirmed in the study as positive points. It is considered from the study that the coastal cities should revitalize natural environment and ensured for the well being of residents and visitors, guided by existing state and federal level management programs, such as the Orla Project.

Keywords: Tourism of Sun and Beach. Coastal Zone. Sustainability Management. Orla Project.

Resumen: Los destinos turísticos de turismo de sol y playa preconizan por el desarrollo del espacio costeiro según los principios de la gestión sostenible, debiendo esta hacerse intensa e inminente frente al proceso de gestión de los recursos naturales, teniendo en cuenta el desarrollo de una forma sistémica de sus funciones económico, ambiental y socio-espacial. En este contexto, el estudio analiza la percepción ambiental de los visitantes a la ciudad de Itapema (SC) en la revitalización de la línea de costa, com la ejecución de um Parque Lineal. Los métodos adoptados para la investigación se apoyan en el paradigma interpretativo, que aborda una visión subjetiva de los fenómenos sociales com el apoyo metodológico del estudio de caso. La principal aportación de la investigación se desarrolla a través de la técnica de entrevistas semi -estructuradas con nueve entrevistados y posteriormente analizada con el método del Discurso del Sujeto Colectivo (CSD). Los resultados mostraron la satisfacción de los visitantes (turistas y excursionistas) para la revitalización de la línea de costa y la estructura del Parque Lineal. Sus testimonios revelan la recuperación de la línea de costa como un recurso natural, el desarrollo de actividades turístico-recreativas en el espacio praial con seguridad, la sociabilidad y la movilidad. Los aspectos territoriales citados como el paseo marítimo, disfrutar de La estructura de ocio para los diferentes grupos de edad, observando el paisaje y mejorar la imagen del municipio también fueron confirmados en la encuesta. Se considera que las ciudades costeras deben revitalizar sus espacios naturales y espacios de valor para la interacción social, guiados por el nivel estatal y federal existentes, tales como los programas de gestión de proyectos de Parques Lineares.

Palabras clave: Turismo de sol y playa. La zona costera. Gestión de la Sostenibilidad. Proyectos de Parques Lineares.

\section{INTRODUÇÃO}

A gestão da sustentabilidade apresenta-se como um tema imperativo para as organizações sociais e produtivas, sobretudo àquelas que, de alguma forma, interferem na sociedade alterando o curso dos recursos naturais e socioespaciais, como é o caso, por exemplo, dos destinos turísticos de sol e praia. $O$ turismo é um dos principais agentes promotores de transformações na paisagem costeira das cidades, atribuindo conforto ambiental ou problemas de ordem estrutural. Sobre este assunto, é evidente a importância da atuação das organizações públicas por uma gestão sustentável sobre a zona costeira, especialmente porque esse ambiente caracteriza-se por comportarem ecossistemas frágeis, por apresentarem riscos iminentes de degradação ambiental pelo uso e ocupação desordenada do solo e, por terem a legislação na maioria das vezes, a favor da proteção e preservação desses locais, mas nem sempre respeitadas pelos agentes intervenientes.

Fatores como a globalização e a tecnologia alavancaram a atividade turística mundial nos séculos XX e XXI, contribuindo para a diversificação de produtos turísticos, segmentação do mercado turístico - com destinos especializados em nichos específicos e, naturalmente, emergindo uma demanda cada vez mais exigente e diversificada. Tendências mundiais apontam que a 
atividade turística movimentará mais de US\$ 1 trilhão, ou seja, mais de R\$ 2 trilhões nos próximos anos, tendo as cidades litorâneas uma grande fatia desse mercado (Organización Mundial del Turismo, 2012). O país emerge no turismo náutico e no turismo de sol e praia, com inúmeras possibilidades de crescimento, devido à potencialidade de paisagens exuberantes e por vezes exóticas, ambientes naturais ainda preservados, além do clima tropical preponderante no Brasil. No entanto, nem todo destino turístico litorâneo tem sido explorado e gerido com responsabilidade social e ambiental, conhecimento e respeito pelos ecossistemas costeiros, como explica Francia (2012).

Muitas das cidades costeiras vislumbram no turismo sua fonte de desenvolvimento econômico, e por isso, requerem ainda mais atenção por uma gestão sustentável quanto à sua organização estrutural, prezando pela qualidade ambiental, segurança e infraestrutura, especialmente para os residentes locais (Silva \& Soriano-Sierra, 2013). Um exemplo que contraria os princípios da gestão sustentável é o município de Tibau do Sul, localizado no estado do Rio Grande do Norte. A praia da Pipa, uma das mais reconhecidas do município supracitado, entrou em colapso ambiental, social e econômico, incorrendo sumariamente na infraestrutura básica (saneamento básico e acessos) devido à ausência de planejamento e gestão (Madeiros et. al., 2013), declinando como destino turístico perante ao mercado.

Cenários como esses tem sido alvo da atenção de especialistas em gestão de turismo como Cooper et. al. (2007) e também em planejamento urbano como Leite \& Awad (2012, p.2), que expõem: "O desenvolvimento sustentável se apresenta mais urgentemente onde mora o problema" e, segundo o mesmo autor, "desenvolver com sustentabilidade pressupõe crença no progresso humano" e também na evolução do conhecimento dos autóctones e dos parceiros do destino turístico (grifo nosso). Essa reflexão é também amparada pelos autores: (Moraes, 2007; Pan, 2010; Lanza \& Randazzo,2013; Kostopoulou, 2013).

No estado de Santa Catarina, a zona costeira, que apresenta 564 quilômetros de linha de costa, exerce forte influência sobre o segmento de turismo de sol e praia, com potencial contribuição para a sustentabilidade social, econômica e ambiental das cidades costeiras (Silva, 2013). Entretanto, a partir da década de 1980, o litoral catarinense vem passando por um profundo adensamento populacional motivado pelo incremento e desenvolvimento do turismo de sol e praia e demais atividades produtivas desenvolvidas no espaço costeiro, incidindo em transformações econômicas, ambientais e socioespaciais, as quais devem ser sinalizadas pela sociedade, na busca de soluções práticas e efetivas (Bitencourt \& Soriano-Sierra, 2008). Ainda, cabe ressaltar que a literatura científica confirma a relevância da gestão da zona costeira para as cidades turísticas, assim como há uma forte contribuição da gestão ambiental para os processos decisórios deste sistema urbano, demonstrando os conflitos e a diversidade de impactos sobre o meio natural, social e econômico. Este assunto é fortemente debatido pelos autores: (Moraes, 2004; Vasconcelos \& Coriolano, 2008; Giumelli, 2008; Costa, 2011; Francia, 2012; Lanza \& Randazzo, 2013 e Scherer, 2013. 
Com base nesse contexto, esta investigação analisa a percepção do visitante do bairro Meia Praia - município de Itapema sobre o processo de revitalização da orla marítima, a partir da implantação do Parque Linear Calçadão (PLC), assim como discute a gestão da sustentabilidade sob a abordagem sistêmica; contextualiza o segmento de turismo de sol e praia e sua principal base histórica.

\section{GESTÃO DA SUSTENTABILIDADE: ABORDAGEM SISTÊMICA}

Uma sociedade sustentável, que versa sobre o desenvolvimento prudente, sob o ponto de vista ambiental, é aquela que atende às necessidades atuais sem comprometer às necessidades das futuras gerações. Premissa esta difundida pelo Relatório Brundtland (1987), da Comissão Mundial sobre Meio Ambiente e Desenvolvimento das Nações Unidas (CMMAD), a qual sinaliza a incompatibilidade entre desenvolvimento sustentável e os padrões de produção e consumo da sociedade contemporânea, evidenciando a importância da relação "indivíduo e meio ambiente" (Ferreira, 2012). Por outro lado, esse conceito é também considerado por especialistas como muito vago e generalista (Pan, 2010).

Na concepção de Claro, Claro \& Amâncio (2008), o foco do desenvolvimento sustentável deve incidir no equilíbrio da proteção ambiental com o desenvolvimento social e econômico, induzindo os gestores de organizações públicas e privadas à responsabilidade comum no processo de mudança, em que a exploração de recursos naturais, investimentos financeiros e tecnologias deverão adquirir uma relação de interdependência. Capra (2006), ao defender sua ideologia sobre a teoria dos sistemas e a lógica do pensamento ecológico contra o pensamento cartesiano e reducionista, explica que há uma mudança na sociedade estrutural contínua, uma teoria ecológica que coloca as ideias numa estrutura científica coesa e coerente. Esta teoria é denominada de teoria dos sistemas, dos sistemas vivos, bem como dos sistemas sociais e dos ecossistemas.

Rodrígues-Díaz \& Espino-Rodríguez (2008) explicam que um destino turístico é um sistema complexo e por isso deve ser gerenciado como um sistema integrado, incluindo medidas e ações baseadas na sustentabilidade, caso contrário o mesmo poderá declinar como no caso de Tibau do Sul citado por Madeiros et. al (2013). Portanto, para que uma organização, incluindo uma cidade, possa atuar sob os princípios da gestão da sustentabilidade, Laszlo (2003) citado por EsquerPeralta, Velazquez \& Munguia, (2008) indica que ela deve se orientar como sendo parte de um sistema maior - uma ecologia de negócios, estendendo-se a um sistema socioeconômico ainda maior. Isto proporciona a necessidade de incorporar a abordagem de sistemas que, de acordo com Esquer-Peralta; Velazquez \& Munguia (2008) pode ajudar na identificação e solução de problemas ambientais e socioeconômicos por meio de uma visão holística para a sustentabilidade, assim como defendem Capra (2006) \& Bertalanffy (1950). Na visão de Beni (2001), um sistema precisa ser dinâmico, flexível, adaptável e, portanto, não é possível entender uma célula, a estrutura de um cérebro, uma cultura, ou o turismo, se esses forem isolados de seus contextos. Para os autores, o relacionamento é a chave. Logo, a teoria geral de sistemas inicialmente debatida por 
Bertalanffy em 1937 apresenta uma relação de interdependência com a premissa do desenvolvimento sustentável, dada a necessidade de compreensão de suas inúmeras dimensões para a gestão do bem estar da sociedade e do meio ambiente, na busca proeminente de um turismo responsável e sustentado. Pan (2010) considera que as cidades sustentáveis devem se auto sustentar-se nos aspectos físicos, envolvendo a população e integrar-se às esferas ambientais, econômicas e socioculturais.

Segundo Moraes Filho (2009) os princípios da sustentabilidade devem ser aplicáveis e gerenciados de forma pragmática nos diversos sistemas que podem sofrer pressão, os quais são entendidos pelo autor, como: a prevenção de danos ambientais e sociais; a precaução; a participação social; a proatividade orientada pelas oportunidades; a compensação; o compromisso com melhorias contínuas e, por fim, o princípio do poluidor pagador, que versa sobre a responsabilidade por uma degradação ambiental severa.

Sachs (2008) e Seiffert (2011) ainda definem desenvolvimento sustentável como a interdependência das dimensões econômica, social, ambiental ou ecológica, as quais devem estar harmoniosamente integradas de forma holística, tal como orienta a teoria geral de sistemas, para assim poderem propor políticas de atuação nas inúmeras esferas da sociedade. No escopo do desenvolvimento sustentável, não há consenso sobre algumas das dimensões da sustentabilidade, pois cada autor as define segundo seus princípios. Portanto, o Quadro 1 ilustra resumidamente as dimensões da sustentabilidade apresentadas na literatura e que subsidiaram os resultados da pesquisa:

Quadro 1 - Dimensões da sustentabilidade

\begin{tabular}{|c|c|c|}
\hline DIMENSÕES & CONCEITOS E VARIAÇÕES & AUTORES \\
\hline $\begin{array}{l}\text { Dimensão } \\
\text { Econômica }\end{array}$ & $\begin{array}{l}\text { É a alocação eficiente dos recursos e investimentos públicos e privados nos } \\
\text { serviços básicos de infraestrutura, de forma equilibrada. Inclui a economia } \\
\text { formal, mas também as atividades informais, que naturalmente proveem } \\
\text { serviços para os indivíduos, aumentando a renda monetária e o padrão de vida } \\
\text { da sociedade. }\end{array}$ & $\begin{array}{l}\text { Silva (1995) } \\
\text { Claro, Claro \& } \\
\text { Amâncio (2008) } \\
\text { Sachs (2008) } \\
\text { Seiffert (2011) }\end{array}$ \\
\hline $\begin{array}{c}\text { Dimensão } \\
\text { Social }\end{array}$ & $\begin{array}{l}\text { Está baseada na redução das diferenças entre a opulência e a miséria, por meio } \\
\text { de uma engrenagem, que engloba, por exemplo, nivelamento do padrão de } \\
\text { renda da população; acesso a educação, moradia e alimentação, entre outros, } \\
\text { com garantias ao atendimento às necessidades biofisiológicas e de formação } \\
\text { intelectual. }\end{array}$ & $\begin{array}{l}\text { Silva (1995) } \\
\text { Bellen (2002) } \\
\text { Sachs (2008) }\end{array}$ \\
\hline $\begin{array}{l}\text { Dimensão } \\
\text { ambiental ou } \\
\text { ecológica }\end{array}$ & $\begin{array}{l}\text { Condiz aos sistemas de sustentação da vida como provedores de recursos, } \\
\text { assim como busca também, por meio da tecnologia, ampliar a capacidade de } \\
\text { renovação dos recursos naturais e diminuir o teor de resíduos no meio natural, } \\
\text { visando à proteção ambiental dos ecossistemas. }\end{array}$ & $\begin{array}{l}\text { Sachs (2008) } \\
\text { Seiffert (2011) }\end{array}$ \\
\hline $\begin{array}{l}\text { Dimensão espacial, } \\
\text { geográfica ou } \\
\text { territorial }\end{array}$ & $\begin{array}{l}\text { Distribuição espacial dos recursos, das populações e das atividades. Seu } \\
\text { objetivo está em reduzir a concentração da população nas áreas } \\
\text { metropolitanas; frear a destruição dos ecossistemas; alavancar a agricultura por } \\
\text { meio de técnicas sustentáveis. }\end{array}$ & $\begin{array}{l}\text { Sachs (2008) } \\
\text { Seiffert (2011) }\end{array}$ \\
\hline $\begin{array}{c}\text { Dimensão } \\
\text { cultural }\end{array}$ & $\begin{array}{l}\text { Respeito à cultura local, uma vez que esta é inerente à história do ser humano, } \\
\text { sendo importante e necessária a conservação do patrimônio histórico - cultural } \\
\text { dentro do sistema. }\end{array}$ & $\begin{array}{l}\text { Sachs (2008) } \\
\text { Seiffeit (2011) }\end{array}$ \\
\hline $\begin{array}{l}\text { Dimensão } \\
\text { tecnológica }\end{array}$ & $\begin{array}{l}\text { Inclusão das inúmeras alternativas tecnológicas para auxiliar os processos } \\
\text { produtivos, adaptando-os a melhor eficiência na prevenção e redução de } \\
\text { recursos ao longo da cadeia produtiva. }\end{array}$ & $\begin{array}{l}\text { Mitidieri (2009 } \\
\text { Seiffert (2011) }\end{array}$ \\
\hline
\end{tabular}

Fonte: Adaptado de Silva (1995); Bellen (2002); Sachs (2008); Claro, Claro \& Amâncio (2008); Mitidieri (2009) \& Seiffert (2011) 
Starik \& Kanashiro (2013) trazem uma nova conotação sobre a teoria de gestão da sustentabilidade, pois, segundo eles, ela implica na formulação, implementação e avaliação de decisões e ações empresariais que estejam relacionadas a aspectos ambientais, sociais e econômicos. Para os autores, essas ações e decisões estão focadas tanto no indivíduo, na organização e na sociedade, num processo de interconexão. Dada à amplitude do potencial de conceitos e a prática da sustentabilidade, alguns valores podem ser incluídos em uma teoria de gestão da sustentabilidade, como defendem os próprios autores (2013, p.16), quais sejam: "inovação, evolução, aprendizagem, colaboração, tenacidade, durabilidade, adaptabilidade, racionalidade, empatia, responsabilidade, ética e justiça, reflexão e espiritualidade". Uma lista de valores vinculada à sustentabilidade tem como característica contribuir para a melhoria dos vários níveis de qualidade de vida das sociedades em nível global, sobretudo às sociedades que vivem nas cidades costeiras.

\section{O SEGMENTO DE TURISMO DE SOL E PRAIA: BREVE HISTÓRICO}

A Zona Costeira Brasileira foi declarada como patrimônio nacional e bem de uso comum do povo na Constituição Federal Brasileira de 1988. De acordo com Silva \& Modesto (2011), a população residente na zona costeira atingiu 50,7 milhões de habitantes em 2010, equivalente a $26,6 \%$ da população brasileira, com uma densidade populacional de aproximadamente 110 hab./ $\mathrm{km}^{2}$. Destaca-se que 19 das 40 regiões metropolitanas brasileiras encontram-se à beira-mar, das quais três estão em Santa Catarina, concentradas nas regiões norte e nordeste catarinense, Foz do Rio Itajaí (centro norte) e capital do estado, Florianópolis (Zamboni \& Nicolodi, 2008; Silva \& Modesto, 2011; Oliveira \& Nicolodi, 2012).

Uma das discussões sobre preservação ambiental e sustentabilidade nas formas de uso e ocupação do solo nas zonas costeiras, reflete a preocupação dos órgãos institucionais em conciliar a proteção dos ecossistemas localizados nesses ambientes com as atividades produtivas. Inúmeras dessas atividades são praticadas na orla, devido à sua dinâmica socioespacial e econômica adjacentes. Assim, verifica-se ao longo das últimas décadas, a incidência cada vez maior de fluxos turísticos se dirigindo às zonas costeiras, com a finalidade de praticar o turismo de sol e praia e constituir segundas residências (Silva, 2013) gerando impactos por vezes irreversíveis, como a destruição de ecossistemas, verticalização da orla, especulação imobiliária gananciosa e, por consequência de tudo isso, a perda de recursos naturais ainda remanescentes.

No Brasil, o segmento de turismo de sol e praia se consolidou nos anos de 1970 com a construção de segundas residências no litoral, localizadas em trechos significativos da orla. 0 estado do Rio de Janeiro - bairro de Copacabana tornou-se um marco desse processo (Moraes, 1995; Macedo, 2004). Segundo Macedo (2004, p.49), “Copacabana era um subúrbio carioca, um bairro distante onde veraneavam ou moravam famílias abastadas", e [...] "durante a primeira metade do século XX consolida-se como uma das mais importantes áreas habitacionais do país, tornando-se padrão de ocupação urbana à beira mar". Ainda no Brasil, outras regiões se destacam 
neste segmento, devido à extensão da orla, a diversidade de ecossistemas marinhos e terrestres e, a influência climática que propicia a incidência de sol e calor o ano todo, como a região Nordeste e outros Estados brasileiros em particular.

Em meados dos anos de 1980, o turismo se consolida como principal atividade econômica nos municípios litorâneos, inicialmente complementando a atividade de pesca artesanal e a agricultura de subsistência (Nemetz, 2004), fortalecendo ainda mais a ocupação do litoral nas três décadas subsequentes, tomando áreas extensas, lineares e muitas vezes contínuas, dando início às atividades ligadas à construção civil para apoiar o crescimento do turismo. O turismo de sol e praia, embora já praticado desde a década de 1970, passou a ser reconhecido oficialmente pelo Ministério do Turismo (Mtur) em 2010, oriundo de estudos de segmentação turística (Brasil, 2010). Segundo o Mtur, o turismo de sol e praia está associado à recreação, entretenimento, contemplação da paisagem combinados à atratividade da praia, caracterizado especialmente por temperaturas quentes ou amenas propícias à balneabilidade. Macedo (2004) complementa, expondo as características que atraem a visitação ao litoral, incluindo a estrutura morfológica de maior valor paisagístico da zona costeira, que segundo ele, é o mar. O autor salienta ainda que o mar contém atributos de alto valor paisagístico, qualificando uma praia e propiciando a preferência por determinado grupo social (Macedo, 2004).

A base legal que permeia as atividades turístico-recreativas e outras praticadas na zona costeira está pautada nos aspectos de gestão patrimonial, ordenamento territorial, gestão de recursos hídricos, gestão da zona costeira e da orla marítima e gestão ambiental (Brasil, 2010). Assim, as atividades do turismo de veraneio desenvolvem-se, de forma geral, em áreas consideradas de preservação permanentes, ecologicamente frágeis, cujos ecossistemas são tanto marinhos quanto terrestres. E exatamente por esses aspectos, cabe mencionar os principais instrumentos legais que legitimam a organização do turismo brasileiro praticado em destinos turísticos litorâneos, quais sejam: Lei no 11.771, de 17 de setembro de 2008, que define a Política Nacional de Turismo; Lei no 7.661, de 16 de maio de 1988, institui o Plano Nacional de Gerenciamento Costeiro; Decreto 5.300, de 2004, que define normas gerais visando à gestão ambiental da zona costeira no país, Lei no 6.938, de 31 de agosto de 1981, que dispõe sobre a Política Nacional de Meio Ambiente; Constituição da República Federativa do Brasil de 1988 define zona costeira como patrimônio nacional (Silva \& Soriano-Sierra, 2013).

Os destinos turísticos de sol e praia se diferem em seu processo de desenvolvimento ao longo do território, em função das diferentes atividades sociais e econômicas locais, ou seja, da dinâmica de uso e ocupação em termos de espaço e tempo. Uma das características predominantes dos balneários está associada à sazonalidade, ou seja, a oscilação da demanda em períodos específicos do ano, predominantemente nos meses mais quentes e de férias, denominado de alta temporada (Beni, 2001). Além dessa, destaca-se também o turismo de massa, por concentrar uma quantidade excessiva de visitantes, equipamentos e infraestruturas, no mesmo espaço geográfico e na mesma época do ano. Macedo (2004) ressalta que, devido a essas características, a vida urbana e até mesmo a economia do muLnicípio passam a se estruturar em 
função exclusiva da temporada de verão. Pierri et. Al (2006, p.154) consideram ainda a "afluência permanente de pessoas que vêm de outras regiões para estabelecer sua moradia no litoral, com expectativas de melhorar sua renda e qualidade de vida, em grande parte pessoas de baixa renda, buscando novas oportunidades".

Dessa forma, a densidade demográfica desses municípios vem aumentando consideravelmente ao longo das últimas décadas, trazendo inevitavelmente impactos negativos para o local, especialmente no tocante aos recursos ambientais, que por vezes não tem capacidade de suporte. Neste cenário, pode-se destacar a intensa urbanização das localidades, incremento da construção civil e, a especulação turística e imobiliária, com a implantação de loteamentos, condomínios verticais e horizontais para fins de segunda residência e empreendimentos turísticos de alto padrão (Silva \& Soriano-Sierra, 2013), além de impactos sociais e econômicos relevantes, com efeito multiplicador de problemas estruturais. Nas mais variadas destinações ao redor do mundo, como as zonas costeiras do Caribe, da Ásia e da América do Sul, a degradação ambiental causada pelo turismo tem provocado perda nos negócios (UNEP, 2002 citado por Pires, 2010). Os turistas, em especial os estrangeiros, com melhor poder aquisitivo, evitam praias poluídas, áreas naturais sujas por material descartável e com esgoto a céu aberto, bem como áreas já descaracterizadas por padrões urbanos de assentamento e arquitetura (Pires, 2010).

Em suma, quando o destino turístico tem como característica principal a zona costeira e o segmento de turismo de sol e praia, sendo a orla o atrativo dos visitantes, é indispensável que haja uma gestão sustentável intensificada para desenvolver ambientalmente, socialmente e economicamente os espaços costeiros. Pesquisas apontam que $60,4 \%$ dos turistas internacionais têm como motivação das viagens a lazer o turismo de sol e praia, enquanto para a demanda turística doméstica, este índice passa a 64,9\% (Brasil; Fipe, 2007; 2009). Esses números evidenciam claramente a profusão da população flutuante nos balneários e a necessidade urgente de preservar e proteger as cidades costeiras.

\section{PROCEDIMENTOS METODOLÓGICOS}

A pesquisa caracterizou-se como exploratória e descritiva, pois buscou registrar, analisar e correlacionar os dados coletados no campo de estudo, conforme Gil (2010). A pesquisa descritiva, neste enfoque, assume a forma de estudo de caso, que segundo Merriam (1998, p. 16) se ajusta a "uma intensiva e holística descrição e análise de uma simples entidade, fenômeno ou unidade social", neste caso, o processo de revitalização da orla marítima do bairro Meia Praia, percebido por uma coletividade, com suas interfaces ambientais, econômicas e sociais, sob a perspectiva da sustentabilidade. 


\subsection{Coleta dos dados}

A técnica adotada para a coleta de dados foi a entrevista semiestruturada, aonde se tencionou conhecer as percepções, o conhecimento, os anseios, experiências e expectativas dos visitantes que frequentam a orla do bairro Meia Praia, no tocante ao processo de revitalização da orla, a partir da implantação do PLC. Para a seleção dos entrevistados, utilizou-se a amostragem não probabilística, que segundo Miguel (1970) é aquela em que o pesquisador escolhe certo elemento do universo do qual seja desconhecido. Ainda nesta concepção, a amostragem divide-se em: por conveniência ou intencional, dada as características da população e o acesso ao grupo representativo de pessoas a que se pretende atingir. Nesta investigação, adotaram-se as duas formas de amostragem.

As entrevistas foram realizadas no período de 15 de janeiro a 24 de março de 2013, numa abordagem pessoal aos visitantes que frequentavam a praia e/ou o PLC e que, na ocasião, aceitaram conceder a entrevista, somando-se ao todo 9 (nove) atores sociais entrevistados. Cabe ressaltar que, para a concretização e validação da entrevista, houve uma condição instituída no delineamento da pesquisa: Os entrevistados deveriam ter visitado o município antes da construção do PLC, ou seja, há pelo menos 5 anos, a fim de que pudessem proceder a comparações (como era e como ficou o espaço costeiro com a revitalização da orla).

Foram feitos registros de áudio das entrevistas e transcritos para confiabilidade do estudo, sendo este fato de plena ciência e concordância do entrevistado, além de o mesmo ter lido e assinado o Termo de Consentimento Livre e Esclarecido. Posteriormente, as entrevistas foram transcritas integralmente para análise e interpretação dos dados segundo o método do Discurso do Sujeito Coletivo (DSC). A observação simples do campo, (Gil, 2010) também foi adotada, pois possibilitou conhecer a realidade apresentada e o processo histórico de implantação do PLC, na orla marítima do bairro Meia Praia.

\subsection{Interpretação e análise dos dados qualitativos}

Para a análise, interpretação e apresentação dos dados da pesquisa, adotou-se o método do (DSC) de Lefévre \& Lefévre (2005). Esse método constitui-se num recurso metodológico que comporta a realização de pesquisas de opiniões coletivas que expressam as distintas Representações Sociais existentes em determinado espaço social sobre um dado tema de pesquisa, constituindo a abordagem interpretativa da realidade social, além de garantir o conhecimento do indivíduo por meio da coletividade (Lefèvre \& Lefèvre, 2003).

\section{CARACTERIZAÇÃO DA ÁREA DE ESTUDO}

Itapema está geograficamente localizada no litoral centro norte do estado de Santa Catarina, região Sul do Brasil, a 60 km da capital do estado - Florianópolis, com área de 59 km². 
Apresenta como limítrofes, os municípios Balneário Camboriú ao norte, Porto Belo ao sul e Camboriú oeste. O município é cortado de norte a sul pela Rodovia BR 101, resultando parcialmente no grande crescimento demográfico e econômico a que experimenta. O Gráfico 1 demonstra a evolução histórica da população flutuante em Itapema na última década, evidenciando crescimento acelerado a partir do ano de 2006, chegando ao ápice em 2010 com aproximadamente 500 mil pessoas presentes na alta temporada de verão. A sazonalidade é bastante acentuada, característica singular de cidades costeiras. Em Itapema, percebe-se a sazonalidade ao comparar a população fixa de 45.797 hab. (IBGE, 2010) com uma população flutuante de 460.000 hab. em aproximadamente quatro meses ao ano.

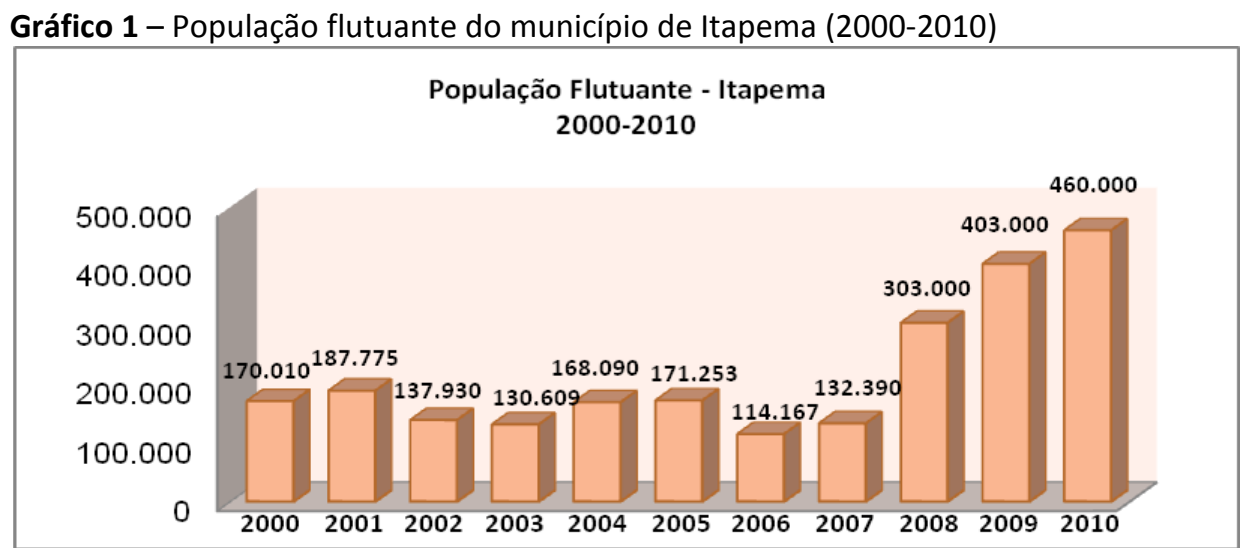

Fonte: Secretaria de Estado de Turismo, Cultura e Esporte (2002, 2006, 2007); Prefeitura Municipal de Itapema, Secretaria de Turismo, 2013

O município tem aproximadamente $14 \mathrm{~km}$ de orla linear, composta por quatro praias: a praia da Mata de Camboriú, a praia da Ilhota, a praia do Cabeço ou Grossa e a praia de Itapema, a qual é dividida em Canto da Praia, praia central de Itapema e Meia Praia (IBGE, 2013). O bairro Meia Praia, com aproximadamente $5 \mathrm{~km}$ de orla, se tornou o ponto de maior interesse dos veranistas, assim como para o comércio e para a indústria da construção civil. Este processo tem submetido Itapema, e especialmente o bairro Meia Praia, a um rápido adensamento dos espaços localizados na orla, por vezes privatizando o espaço praial de forma ilegal, impondo pressão sobre a infraestrutura urbana, levando ao avanço da ocupação sobre áreas frágeis, ocasionando com isso problemas de degradação ambiental, perda de ecossistemas relevantes e da cultura açoriana, com a redução, quando não, a extinção da pesca artesanal. Com base neste panorama, o bairro Meia Praia constitui o recorte geográfico da área de estudo e, principalmente, porque foi nele que ocorreu a revitalização da orla marítima.

\section{CONTEXTUALIZAÇÃO DO PROCESSO DE REVITALIZAÇÃO DA ORLA MARÍTIMA COM A IMPLANTAÇÃO DO PARQUE LINEAR CALÇADÃO}

A gestão pública municipal de Itapema deu início em 2007, ao convênio com o Ministério do Meio Ambiente (MMA) e Secretaria do Patrimônio da União (SPU) para iniciar o processo de 
implementação do Projeto de Gestão Integrada da Orla Marítima (Projeto Orla) (Brasil, 2006) iniciado no Brasil em 2001 como um dos instrumentos do Plano Nacional de Gerenciamento Costeiro (PNGC). O Projeto Orla pressupõe a importância em distinguir e mensurar a definição do perfil socioeconômico para cada trecho da orla para fins de gestão, como também para mapear as relações sociais e atividades econômicas locais. Sua implementação nas cidades costeiras dá-se de forma integrada entre o poder executivo municipal e o órgão federal, cujos objetivos visam o resgate da atratividade do espaço público de lazer, o planejamento do uso e ocupação do espaço urbano, a preservação da área costeira contra a poluição das águas fluviais e construções irregulares e, a promoção da recuperação da vegetação de restinga (Brasil, 2006). Além disso, busca-se propiciar melhor aproveitamento e adequação dos espaços naturais e do espaço praial para a população local, além de organizar a orla para fins turístico-recreativos (Oliveira \& Nicolodi, 2012). Seguindo os fundamentos do Projeto Orla, a gestão pública de Itapema juntamente à comunidade local, numa gestão participativa, decidiu pela implantação de um parque linear em formato de calçadão, no trecho da orla do bairro Meia Praia, excluindo a possibilidade de construir avenida de rolamento à beira mar. Sendo assim, a primeira etapa de execução do projeto foi concluída no ano de 2008 e a quarta e última etapa, que se estende até a divisa com o município de Porto Belo, foi concluída em dezembro de 2012.

Tendo em vista o histórico de participação da comunidade e os processos decisórios tomados junto à Gerência Regional do Patrimônio da União, verificou-se que esta arquitetura gerou impactos sobre a população local e seus visitantes, nas dimensões ambientais, socioculturais, espaciais, estéticas e econômicas, segundo a percepção dos atores sociais. Por conseguinte, o trabalho está ancorado nas interpretações dos visitantes que vivenciaram o processo de revitalização da orla do bairro Meia Praia.

\section{ANÁLISE E DISCUSSÃO DOS RESULTADOS}

O estudo caracterizou-se por apresentar a abordagem interpretativa do fenômeno social, a qual pressupõe a percepção dos visitantes acerca de uma transformação do espaço social de lazer, ressaltando que este espaço está alicerçado por uma imagem visual e cognitiva concreta. Ademais, buscou-se também o conhecimento dos visitantes sobre a gestão da sustentabilidade local. Os depoimentos sínteses (DSC's) são apresentados a seguir:

A primeira questão se interessou em saber qual o motivo pelo qual as pessoas visitavam Itapema. As respostas foram variadas, sendo o principal motivo pela segunda residência, uma forte característica dos balneários, como já comentado. Dentre as respostas presentes nos DSC's, destacam-se: [visita a parentes]; [férias de fim de ano]; [estrutura da praia]; [tranquilidade]; $e$ [proximidade da residência]. Para essas respostas, vale a pena apontar uma reflexão: dos seis motivos relatados pelos visitantes, dois deles fazem referência à orla e à praia, como a estrutura $\mathrm{e}$ a tranquilidade. Os demais são motivos familiares. Dados como esses podem fazer a diferença 
para o planejamento de marketing do destino, inclusive aprimorando a promoção da orla, como principal atrativo do local, já que foi explicitamente evidenciada.

A segunda questão, estabelecida como pré-condição para se concretizar a entrevista, objetivou saber se o visitante havia frequentado a orla do bairro Meia Praia antes da construção do PLC. Esta pergunta foi elaborada tendo em vista a importância em legitimar as respostas dos participantes. Dos 9 visitantes entrevistados, todos relataram frequentar a praia do bairro Meia Praia antes da implantação do PLC. Dentre os anos que passaram a visitar o município estão: 1991 (1); 1992 (1); 1996 (1); 1998 (2); 1999 (2) e 2000 (2). Este resultado demonstra que todos os entrevistados já tinham o conhecimento e a imagem visual do local antes de sua transformação física e estrutural.

A terceira questão buscou conhecer a opinião dos visitantes sobre a orla e o PLC - como ela se encontra no presente. As respostas demonstram o contentamento e a satisfação dos visitantes com o PLC, em especial quando se questionou sobre a limpeza da praia e da orla; a paisagem e beleza cênica e seus valores estéticos; acesso a praia adequados; orla planejada e organizada e, se o PLC contribui para a socialização das pessoas. Essas variáveis satisfizeram positivamente $100 \%$ dos informantes. Sobre a manutenção dos equipamentos instalados, 33\% dos entrevistados disseram não haver manutenção, pois é evidente a degradação dos corrimões que apoiam as rampas de acesso à praia, as cercas de proteção da vegetação encontram-se depredadas, assim como a ocorrência de ferrugem em vários dos aparelhos de ginástica. Outras variáveis foram respondidas com qualidade parcial, como a preservação da vegetação nativa; infraestrutura adequada; mobilidade urbana para os pedestres e acessibilidade para portadores de necessidades físicas e visuais. Quando questionado se a orla apresenta uma gestão sustentável, 33\% disseram que não, enquanto que 66\% disseram que sim (Gráfico 2):

Gráfico 2- Percepção dos visitantes sobre a orla e o Parque Linear Calçadão

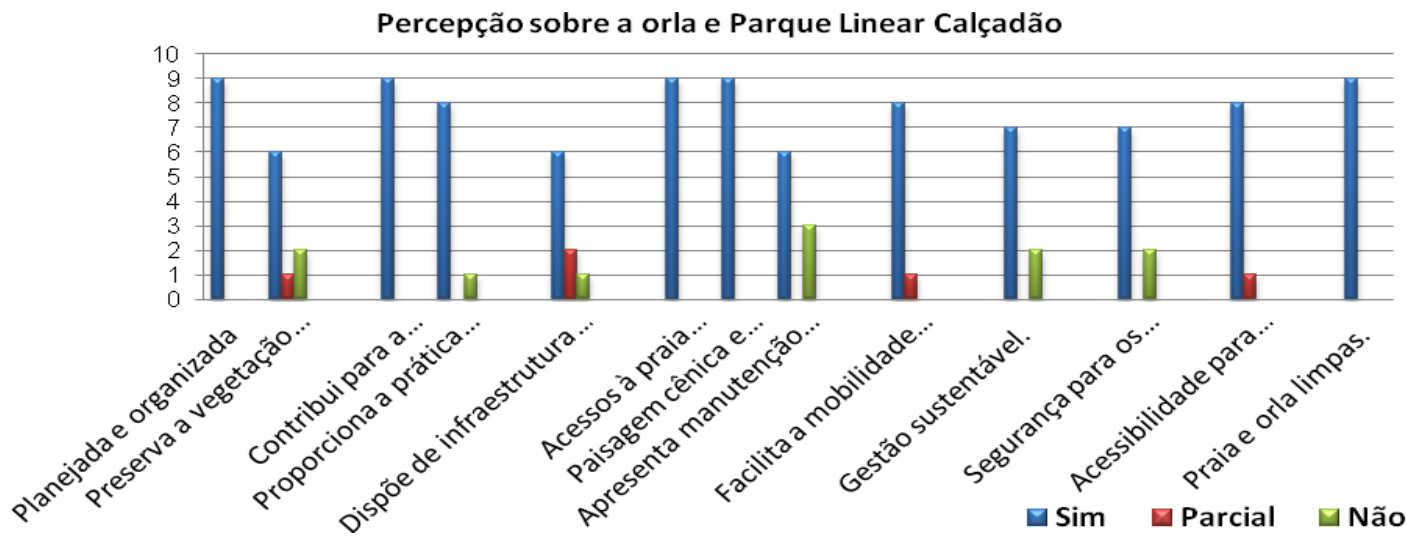

Fonte: Silva (2013)

Com relação aos comentários dos visitantes sobre o PLC, alguns deles destacaram a valorização conferida à orla por parte da gestão pública, como também o cuidado com a cidade, enfatizando que após a construção do PLC a cidade ficou mais atraente e bonita. Para muitos foi 
um avanço em termos de planejamento urbano. Sobre este ponto, Macedo (2004) exclarece que a partir de um núcleo básico, pode-se equipar um local para receber um número maior de usuários e oferecer-lhes mais e melhores serviços, mesmo sendo o mar e a praia o principal motivo de visitação; tal como ocorreu com o bairro Meia Praia em Itapema. O DSC sobre este depoimento é apresentado a seguir:

\section{IC - Evolução urbanística e ordenamento da orla}

DSC: Ah, melhorou muito. Agora a gente pode caminhar tanto na areia quanto no calçadão. Valorizou não só a orla, mas os imóveis também... valorizou a cidade como um todo, embelezou a orla. Ficou mais regularizada, ficou mais administrada, se vê mais a presença do Estado ali... Hoje em dia a estrutura é muito melhor, dá para desfrutar mais. Ficou uma praia bem mais bonita, com melhores acessos da avenida para a praia. A limpeza, a cidade está bem mais atraente e bonita. Melhorou muito, evoluiu.

\section{IC - Avanço para o município}

DSC: Essa estrutura foi um avanço para o município, ficou bem melhor. A gente olha para isso tudo e só tem que elogiar. Congratular o prefeito. Tá muito bom mesmo. Certamente recomendaria para outras pessoas conhecerem.

Alguns dos entrevistados referiram-se à orla antes do PLC como uma praia abandonada, rústica e sem planejamento. Por outro lado, alguns alegaram que preferiam Meia Praia antes do adensamento populacional ocorrido nos últimos anos, por ser uma cidade mais pacata e tranquila. Para este grupo, a cidade não tem infraestrutura para atender a população fixa e, nem tampouco a flutuante. A esse respeito, novamente Macedo (2004) colabora, afirmando que os municípios, cuja renda advém do turismo de sol e praia, regularmente entram em estado de deficiência crônica em quase todos os setores, a exemplo dos serviços de abastecimento de água, ausência total da rede de esgotos, redes viárias precárias. A seguir, os discursos que representam estes depimentos:

\section{IC - Anteriormente a praia era rústica e a orla apresentava-se abandonada}

DSC: Antigamente a orla era abandonada, cheio de budega, quiosque. As pessoas tinham que andar no meio de vegetação, caminhar só na areia. A praia era mais rústica, menos organizada.

\section{IC - O PLC provocou maior adensamento populacional e não há estrutura de suporte na cidade}

DSC: Eu preferia a Meia Praia antes da Implantação do calçadão, por ser uma cidade mais calma e tranquila. Acho que não tem infraestrutura para atender tanta gente e, tende a ficar cada vez pior. São prós e contras. O lado negativo é a cultura que está se perdendo. 
A quarta questão buscou compreender a percepção dos visitantes sobre uma obra urbanística como o PLC para um destino turístico como Itapema, especialmente no formato de parque linear. O primeiro discurso traz o termo "revitalização", cuja percepção do visitante referese à estrutura implantada como o grande diferencial. "Com ela todas as pessoas tem acesso a um espaço de lazer ligado ao ambiente natural, desde crianças, idosos, deficientes, etc." Novamente foi mencionado o PLC como uma nova atração turística, comparada ao município vizinho Balneário Camboriú, que já se consolidou como um dos destinos de sol e praia mais visitados do país. Por fim, houve um depoimento de 3 dos 9 entrevistados que destacou os banheiros químicos como um equipamento precário e fora do contexto da estrutura implantada na orla, inclusive sugerindo à gestão pública repensar em outra alternativa, pois acaba denegrindo a imagem conquistada, indo totalmente contra a gestão sustentável. Os DSC's acerca desta questão é visualizada a seguir:

\section{IC - Revitalização da orla, com nova estrutura de lazer}

DSC: Revitalização! Eu gostei bastante por causa da estrutura. Tem acesso para as crianças, não tem perigo de se machucarem, elas podem brincar à tarde. Achei mais fácil para fazer caminhada, o acesso para deficientes. Eu procurei aqui por causa dessa estrutura. É uma estrutura ótima, traz conforto para as pessoas. Eu acho que a estrutura, quanto melhor, mais pessoas vai atrair para o local, pois antes era uma praia sem estrutura, com mato, com acesso mais difícil. As pessoas hoje tem a opção de fazer uma caminhada, ficar sentadas ali com tranquilidade.

\section{IC - É uma nova atração turística da cidade}

DSC: A repercussão foi muito boa. O local está muito visitado. Eu acho que vai atrair muito mais turistas pra cá. As pessoas já comparam Meia Praia com Balneário Camboriú. Mas acho que deveriam fazer mais marketing para o pessoal de fora conhecer, é preciso propaganda, pois é muito belo.

\section{IC - Os banheiros químicos deveriam ser retirados e pensar em outra alternativa}

DSC: Os banheiros químicos, que não acho higiênicos aqui na orla, deveria ser melhor planejado.

No intuito de expandir o conhecimento e a discussão acerca do assunto, a quinta questão se propôs, a saber, se os visitantes conheciam outros destinos litorâneos cuja orla é semelhante à do bairro Meia Praia em Itapema. Dos 9 entrevistados, 60\% disseram não conhecer nenhum balneário com a estrutura do PLC, enquanto que $40 \%$ conheciam, citando os destinos de sol e praia: Aracaju (SE), Rio de Janeiro (RJ), Salvador (BA), Fortaleza (CE), João Pessoa (PB), Maceió (AL), Santos (SP) e Balneário Camboriú (SC). Um dos visitantes citou ainda a Suíça, na Europa, mas justificou que a extensão da orla é pequena.

Cabe salientar que a estrutura presente em muitos dos municípios litorâneos do país é resultado de políticas públicas descentralizadas, como o Projeto Orla, fruto de arranjos políticos institucionais para a descentralização da orla. No caso do Brasil, o Plano Nacional de Gerenciamento Costeiro - Lei $n=7.661$, de 1988, foi o marco para a gestão ambiental da zona 
costeira no país, no qual instituiu um zoneamento e um conjunto de normas de caráter obrigatório, sancionado pelo poder de polícia. Além desse, tem-se o Decreto no 5.300 de 2004, que estabeleceu critérios para a gestão da orla marítima, ao contrário de muitos países, em que não há uma política para a gestão integrada da zona costeira, como exemplificam Lanza \& Randazzo (2013). Em uma investigação recente, os autores constataram sérios problemas de ordem ambiental, urbana e fundiária na maior ilha do Mediterrâneo - a ilha de Sicília na Itália, em que a erosão costeira ocupou áreas de residências a beira mar, causando destruição e perdas materiais.

Os depoimentos sobre a quinta questão apresentam-se a seguir:

\section{IC - Planejada como esta e que integra uma estrutura, não conheço}

DSC: Tão planejada como essa e que apresenta preservação do meio ambiente, limpeza, duchas, tanta coisa junta... não conheço. Além disso, temos casa aqui e então acabamos não viajando para outros lugares.

$$
\text { IC - Sim }
$$

DSC: Sim. Aracaju. Aracaju tem a melhor estrutura, uma orla construída muito bacana. Fazem uns 2 anos. A estrutura deles é muito melhor. Rio de Janeiro, Salvador, Fortaleza, João Pessoa, tem uma orla muito bonita, muito cuidada. Balneário Camboriú tem orla organizada, com calçadão. Fortaleza, Maceió tem uma orla com calçadão com quiosque, duchas. Tem alguns países estrangeiros que tem, mas são pequenos, tem na Suíça, na Itália, mas a orla é pequena.

O sexto questionamento procurou identificar se Itapema apresenta uma gestão sustentável da orla, tendo em vista as dimensões sociais, ambientais e econômicas. Um dos discursos coletivos evidenciou a socialização das pessoas a partir da construção do PLC, por meio de seu espaço de convivência, com estrutura de lazer. A esse respeito, Macedo (2004) confirma o depoimento do grupo, ao relacionar o espaço praial ao local onde se desenvolvem as formas de lazer urbano, como jogos, pescaria, esportes náuticos, contemplação da paisagem e do mar. Para o autor, este espaço proporciona situações de relacionamento social. Já no aspecto econômico, percebeu-se um incremento de divisas oriundo do crescimento da demanda de turistas, e, junto a este fator, a oferta de mais empresas prestadoras de serviços de alimentação e hospedagem. No entanto, foi mencionada a precariedade da infraestrutura urbana do município, sobretudo, nos meses de maior concentração de pessoas na cidade. Para este grupo, a gestão sustentável ainda não existe, uma vez que a orla não se encontra isolada do município e, por sua vez, o município ainda necessita de planejamento urbano. Os depoimentos, a partir dos DSC's são visualizados a seguir:

\section{IC - Sim, é sustentável}

DSC: Acredito que sim, tudo foi planejado. Sim, é sustentável. 


\section{IC - No aspecto social propiciou a encontro das pessoas, um espaço para convivência}

DSC: Social, sem dúvida. Socialmente, propiciou a encontro das pessoas, um espaço para convivência. Agora a gente tem muito mais acesso à parte social, as pessoas podem sentar, podemos tomar sorvete, as pessoas idosas podem jogar bocha.

\section{IC - Economicamente valorizou muito a cidade, os imóveis e incrementou o comércio local}

DSC: Eu achei que economicamente valorizou a cidade, os prédios ficaram mais bonitos, valorizados, mais limpos. Eu percebo melhorias nos bares e restaurantes, houve de uns anos pra cá mais oferta de serviços. E também a geração de dinheiro das pessoas que visitam a cidade.

\section{IC - É necessário investir mais em infraestrutura}

DSC: Eu acho que a comunidade como um todo precisa de mais infraestrutura, especialmente no período entre Natal e Ano Novo.... v valor que se paga aqui do IPTU que é um dos mais caros do Estado, ter-se-ia que ter um retorno maior a esse tributo, investir mesmo em infraestrutura.

\section{IC - Não apresenta uma gestão sustentável}

DSC: Eu acho que não tem gestão sustentável. Mas como esse ano foi a conclusão do calçadão, acho que eles tendem a melhorar.

A carência de infraestrutura básica foi novamente percebida na sétima questão, o que demonstra ser este um fator que merece atenção especial e emergencial pela gestão pública. Objetivou-se conhecer a opinião dos visitantes acerca da crescente urbanização dos destinos litorâneos. Quando o grupo de visitantes relatou a deficiência de infraestrutura, muitos compararam Itapema a outros destinos turísticos, expandindo a consciência de infraestrutura para além do saneamento e mobilidade urbana. Os discursos evidenciaram a qualidade e capacidade do atendimento ao visitante, a limpeza das vias públicas e, é claro, o atendimento à população flutuante com água potável. Este DSC é apresentado a seguir:

\section{IC - Há uma ineficiência de infraestrutura básica}

DSC: O problema é que muitas cidades não têm estrutura. Há falta de planejamento. Fica difícil vir para praia, gastar dinheiro e não ter o mínimo de infraestrutura para tomar um banho. Muitas cidades não têm infraestrutura que comporte o contingente de pessoas, quanto à questão de água, falta água. O maior prejuízo é a limpeza, muita agitação. Lá no Nordeste mesmo, eles não têm essa estrutura toda perto da praia, é sempre mais abandonado.

A segunda IC reconheceu a urbanização com um processo natural, decorrente do crescimento da população e sua motivação por cidades litorâneas, como pode ser visto no DSC:

\section{IC - Interessante, desde que seja organizado}


DSC: Isso é um processo natural. Conforme vai aumentando a população, as praias vão aumentando cada vez mais. Aqui é tudo muito mais organizado, o Guarujá também a mesma coisa, vão urbanizando, vai crescendo, mercado, tudo pertinho da praia. Ah, eu acho muito legal.

Pode-se considerar que os atores sociais que satisfazem os visitantes de um destino turístico são indivíduos importantes para avaliar a qualidade do produto, que neste caso, é o conforto ambiental proporcionado pelo PLC. Para os turistas, a qualidade percebida, serviços utilizados e imagem associada ao produto/destino faz parte de um conceito de atributos múltiplos, o que significa que as percepções de valor podem flutuar em uma população. Contudo, quando o resultado das percepções aponta para interpretações semelhantes do pesquisador para com os indivíduos do grupo, verifica-se a realidade exposta na forma de um diagnóstico confiável, levando a possíveis decisões assertivas pela gestão pública/ privada, se assim souberem utilizar os conhecimentos gerados, uma vez que a construção do conhecimento é um processo social.

Os resultados da percepção e do conhecimento expostos na forma de depoimentos demonstram que os visitantes dos destinos turísticos conseguem compreender as dimensões da sustentabilidade em cada variável questionada, ainda que não seja com uma linguagem técnica, mas explicitam sua fala alicerçada pela vivência e conhecimento proveniente de viagens, leituras e experiências. Abaglia e Maciel (2004) explicam que cada local ou região dispõe de diferentes combinações de características e bens coletivos - físicos, sociais, econômicos, culturais, políticos, institucionais - que influenciam sua capacidade de produzir conhecimento, de aprender e de inovar, e os atores sociais constituem o capital intelectual do ambiente, com suas diversas interações.

\section{CONSIDERAÇÕES FINAIS}

A pesquisa revelou alguns pontos negativos de ordem estrutural e gerencial no PLC, segundo a percepção dos visitantes, mas em sua maioria, os atores sociais do destino mostraramse satisfeitos com a revitalização e a preocupação ambiental pela orla marítima. Pode-se considerar que o processo de revitalização da orla do bairro Meia Praia apresenta-se como referência para uma cidade costeira, que seguiu os princípios de orientação do Projeto Orla e de ordenamento da legislação vigente, na busca proeminente por uma gestão sustentável de seu espaço costeiro.

Verificou-se que o PLC tem contribuído com a qualidade ambiental e paisagística da orla marítima do bairro Meia Praia, em especial pela recuperação da beleza cênica e reflorestamento da vegetação de restinga, além de favorecer a socialização dos frequentadores da orla e resgatar a atratividade do espaço público de lazer para todas as faixas etárias, além de elevar a autoestima do morador e do visitante habitué. Percebeu-se também que o grupo de visitantes reconhece os fundamentos e/ou objetivos da gestão da sustentabilidade para as cidades costeiras, o que pode ser verificado na prática, por meio da explicitação dos discursos individuais. 
Por fim, os objetivos da pesquisa foram alcançados, na pretensão em compreender a visão, a percepção e as experiências de um grupo social que apresenta características peculiares capazes de avaliar uma obra pública como o PLC. No entanto, o processo de avaliação e verificação de obras públicas que transformam a paisagem e mudam o cotidiano de uma comunidade e, que legitimam a legislação ambiental, deve ser permanentemente monitorado pelos atores sociais de todo e qualquer território. Para garantir a sustentação e a vitalidade das funções econômica, ecológica e sociocultural no espaço litorâneo, de forma simultânea, torna-se necessário que os municípios desenvolvam ações de planejamento e gestão para a integração das mesmas, de modo a reduzir conflitos e eliminar antagonismos, com base no conhecimento da população local e flutuante, com vistas a atender os princípios da sustentabilidade e promover o turismo de qualidade.

\section{REFERÊNCIAS}

Abaglia, S. \& Maciel, M. L. (2004). Informação e conhecimento na inovação e no desenvolvimento local. Ci. Inf., Brasília, v. 33, (3), pp. 9-16.

Bellen, H. M. V. (2002). Indicadores de sustentabilidade: uma análise comparativa. Tese (Doutorado em Engenharia de Produção), Universidade Federal de Santa Catarina (UFSC), Florianópolis.

Beni, M. C. (2001). Análise estrutural do turismo. 6. ed. São Paulo: SENAC.

Bertalanffy, L. Von. (1950). The teory of open systems in physics and biology. Science: New York.

Bitencourt, N. de L. da R. \& Soriano-Sierra, E. J. (2008). Gestão ambiental integrada da orla marítima: estudo de caso, conflitos de uso do canal da Barra da Lagoa - Ilha de Santa Catarina, Brasil. Revista de Estudos Ambientais, 10, (1), pp. 65-73.

Brasil. Ministério do Meio Ambiente. (2006). Projeto Orla: fundamentos para Gestão Integrada. Secretaria de Qualidade Ambiental; Ministério do Planejamento, Orçamento e Gestão, Secretaria do Patrimônio da União, Brasília, DF, Brasil.

Brasil. Ministério do Turismo. (2010). Turismo de sol e praia: orientações básicas. 2. ed. Brasília, DF: Ministério do Turismo.

Capra, F. (2006). O ponto de mutação. Trad. de Álvaro Cabral. São Paulo: Cultrix.

Claro, P. B. de O.; Claro, D. P. Amâncio, R. (2008). Entendo o conceito de sustentabilidade nas organizações. Revista de Administração, 43, (4), pp. 289-300.

Cooper, C. et. al. (2007). Turismo: princípios e práticas. Trad. de A. S. 3. ed. Porto Alegre: Bookman.

Costa, N. B.R. da. (2011). Impactos socioambientais do turismo em áreas litorâneas: um estudo de percepção ambiental nos balneários de Praia de Leste, Santa Teresinha e Ipanema - Paraná. Revista Geografar, 6, (2), pp. 151-181. 
Esquer-Peralta, J.; Velazquez, L. \& Munguia, N. (2008). Perceptions of core elements for sustainability management systems (SMS). Management Decision, 46, (7), pp. 1027-1038.

Ferreira, D. D. M. (2012). Gestão e uso da água na suinocultura: um diagnóstico a partir da comparação de pegadas hídricas. Tese- (Doutorado em Engenharia e Gestão do Conhecimento). Universidade Federal de Santa Catarina, Florianópolis.

Francia, J. A. B. (2012). Ocupación del território litoral en ciudades turísticas de México. Bitacora, Universidad Nacional de Colombra, Bogotá, pp. 41-52.

GIL, A. C. (2010). Como elaborar projetos de pesquisa. 5. ed. São Paulo: Atlas.

Giumelli, O. D. (2008). Análise da seleção de indicadores de turismo responsável com foco nos municípios litorâneos do estado de Santa Catarina, Brasil. Dissertação- (Mestrado em Turismo e Hotelaria), Universidade do Vale do Itajaí, Balneário Camboriú.

Instituto Brasileiro de Geografia e Estatística (IBGE) (2010). Indicadores sociais municipais: uma análise dos resultados do universo do Censo Demográfico 2010. Disponível em: <http://www.ibge.gov.br/cidadesat/link.php?codmun=420830> Acesso em 08 abr. 2013.

Instituto Brasileiro de Geografia e Estatística (IBGE) (2013). Cidades@. Santa Catarina - Itapema. Disponível em: <http://www.ibge.gov.br/cidadesat/topwindow.htm?1> Acesso em 19 mar. 2013.

Kostopoulou, S.(2013). On the Revitalized Waterfront: Creative Milieu for Creative Tourism. Sustainability, 5, pp. 4578-4593.

Lanza, S. \& Randazzo, G. (2013).Tourist-beach protection in north-eastern Sicily (Italy). Journal of Coastal Conservation, 17, pp. 49-57.

Lefèvre, F. \& Levèvre, A. M. C. (2003). O Discurso do Sujeito Coletivo: um novo enfoque em pesquisa qualitativa (desdobramentos). Caxias do Sul, RS: EDUCS.

Lefèvre, F. \& Levèvre \& A. M. C. (2005). Depoimentos e discursos: uma proposta de análise em pesquisa social. Brasília: Líber Livro.

Leite, C.; Awad, J. di C. M (2012). Cidades sustentáveis, cidades inteligentes: desenvolvimento sustentável num planeta urbano. Porto Alegre: Bookman.

Macedo, S. S. (2004). Paisagem, litoral e formas de urbanização. In: Projeto Orla: subsídios para um projeto de gestão. Ministério do Meio Ambiente, Secretaria de Qualidade Ambiental nos Assentamentos Humanos / Ministério do Planejamento, Orçamento e Gestão, Secretaria do Patrimônio da União, Brasília, DF, pp.4564.

Madeiros, C. et. al. Com infraestrutura precária, cidade potiguar vive entre luxo turístico e miséria do povo. Universo on line; Disponível em: http://eleicoes.uol.com.br/2012/album/2012/09/13/tibau-do-sul-rn.htm. Acesso em: 05 nov. 2013.

Merriam, S. B. (1998). Qualitative research and case study applications in education. San Francisco: JosseyBass. 
Miguel, G. B. (1970). Métodos de pesquisa pedagógica. São Paulo: Loyola.

Mitidieri, T. da C. (2009). Construção do futuro e sustentabilidade. Tese (Doutorado em Engenharia e Gestão do Conhecimento), Universidade Federal de Santa Catarina, Florianópolis.

Moraes, A. C. R. (1995). Os impactos da política urbana sobre a zona costeira. Programa Nacional do Meio Ambiente. Brasília.

Moraes, A. C. R. (2004). Classificação das praias brasileiras por níveis de ocupação: proposta de uma tipologia para os espaços praiais. In: Brasil, Ministério do Meio Ambiente, Secretaria de Qualidade Ambiental nos Assentamentos Humanos / Ministério do Planejamento, Orçamento e Gestão, Secretaria do Patrimônio da União. Projeto Orla: subsídios para um projeto de gestão. Brasília, DF, pp. 33-44.

Moraes, A.C.R. (2007). Contribuição para a gestão costeira do Brasil: elementos para uma geografia do litoral brasileiro. Annablume, São Paulo.

Moraes Filho, R. A. (2009). Sociedade e meio ambiente. In: Albuquerque, J. de L. Gestão ambiental e responsabilidade social: conceitos, ferramentas e aplicações. São Paulo: Atlas.

Nemetz, S.M.M.C.C. (2004). Balneabilidade de praias do litoral centro-norte de Santa Catarina: estudo de percepção ambiental. Dissertação (Mestrado em Engenharia Ambiental) -Universidade Regional de Blumenau.

Oliveira, M. R. L. de \& Nicolodi, J.L. (2012). A gestão costeira no Brasil e os dez anos do Projeto Orla: uma análise sob a ótica do poder público. Journal of Integrated Coastal Zone Management. 24 abr. 2012. pp. 8998. Disponível em: <http://www.aprh.pt/rgci/pdf/rgci-308 Oliveira.pdf>. Acesso em: 20 mar. 2013.

Organizacion Mundial Del Turismo (2012). Panorama OMT del turismo internacional. Edicion 2012. Disponível em: < http://dtxtq4w60xqpw.cloudfront.net/sites/all/files/pdf/unwto highlights12 sp hr.pdf> Acesso em 16 maio 2013.

PAN, W. (2010). Ranking Sustainable cities: a critical review. In: Proceedings of the First International Conference on Sustainable Urbanization, 2010, Hong Kong, China, pp. 1147-1156.

Pierri, N.et. al.(2006). A ocupação e o uso do solo no litoral paranaense: condicionantes, conflitos e tendências. Desenvolvimento e Meio Ambiente, 13, pp. 137-167.

Pires, P. dos S. (2010). Turismo e meio ambiente: relação de interdependência. In: Philippi Jr., A.; Ruschmann, D. van de M. Gestão ambiental e sustentabilidade no turismo. Barueri, SP: Manole, cap. 1, pp. 4-29. (Coleção Ambiental).

Rodrígues-Díaz, M. \& Espino-Rodríguez, T. F. (2008). A Model of Strategic Evaluation of a Tourism Destination Based on Internal and Relational Capabilities. Journal of Travel Research, USA, may, pp. 368380.

Sachs, I. (2008). Desenvolvimento: includente, sustentável, sustentado. Rio de Janeiro: Garamond.

Sachs, I. (2004). Desenvolvimento Sustentável - desafio do século XXI. Ambiente \& Sociedade, 7(2), pp. 214-216. 
Scherer, M. (2013). Gestão de praias no Brasil: subsídios para uma reflexão. Journal of Integrated Coastal Zone Management, 1, pp. 3-13.

Secretaria de Estado, Cultura e Esporte de Santa Catarina (2007). Sinopse Comparativa de 2005, 2006 e 2007 - janeiro e fevereiro. Estado de Santa Catarina/SANTUR (Pesquisa Mercadológica: Estudo da Demanda Turística).

Secretaria de Estado, Cultura e Esporte de Santa Catarina (2006). Sinopse Comparativa de 2003, 2004, 2005 e 2006 - janeiro e fevereiro. Estado de Santa Catarina/SANTUR (Pesquisa Mercadológica: Estudo da Demanda Turística).

Seiffert, M. E. B. (2011). Gestão ambiental: instrumentos, esferas de ação e educação ambiental. 2a ed. São Paulo: Atlas.

Silva, C. A. M. da \& Modesto, F. (2012). Cidades em zonas costeiras brasileiras: rumo à resiliência? In: VI Encontro Nacional da Anppas, 18 a 21 de setembro de 2011, Belém (PA), Brasil. Anais... Associação Nacional de Pós-Graduação e Pesquisa em Ambiente e Sociedade, 2012. Disponível em: http://www.anppas.org.br/encontro6/arquivos/Programacao preliminar versao 2.pdf. Acesso em: 29 ago. 2013.

Silva, J. A. (1995). Direito ambiental constitucional. 2. ed. São Paulo: Malheiros.

Silva, M. E. M. da. (2013). Gestão sustentável da orla marítima em destinos turísticos costeiros: a percepção dos atores sociais. Dissertação - (Mestrado em Engenharia e Gestão do Conhecimento) - Universidade Federal de Santa Catarina, Florianópolis.

Silva, M. E. M.da. \& Soriano-Sierra, E. J.(2013). Gestión sustentable de la orla marítima em destinos turísticos: una perspectiva social sobre el projecto ORLA. Estudios y Perspectivas en Turismo, Buenos Aires, 22, (5), pp. 805-827.

Starik, M. \& Kanashiro, P. (2013). Toward a theory of sustainability management: uncovering and integrating the nearly obvious. Organization \& Environment, 26, (1), pp. 7-30.

Vasconcelos, F. P. \& Coriolano, L. N. (2008). Impactos socioambientais no litoral: um foco no turismo e na Gestão Integrada da Zona Costeira no estado do Ceará/Brasil. Revista de Gestão Costeira Integrada, 2, (8), pp. 259-275.

Zamboni, A. \& Nicolodi, J.L. (Org.). Macrodiagnóstico da Zona Costeira e Marinha do Brasil, 242p. Ministério do Meio Ambiente, Secretaria de Mudanças Climáticas e Qualidade Ambiental. Brasília. DF.

Artigo recebido em: 02/05/2014. Artigo aprovado em: 15/04/2015. 